\begin{tabular}{|c|c|c|c|c|}
\hline & $\begin{array}{l}\text { Screened } \\
\%(N)\end{array}$ & $\begin{array}{l}+\operatorname{screen} \% \\
\text { (N) }\end{array}$ & $\begin{array}{l}\text { Families provided } \\
\text { resources (among } \\
\text { all families) }\end{array}$ & $\begin{array}{l}\text { Families provided } \\
\text { resources (among } \\
\text { families with + } \\
\text { screen) }\end{array}$ \\
\hline Food Insecurity & $98.0 \%(678)$ & $46.1 \%(319)$ & $45.4 \%(314$ of 678$)$ & $98.4 \%(314$ of 319$)$ \\
\hline Housing Instability & $97.5 \%(675)$ & $13.2 \%(91)$ & $11.3 \%(78$ of 675$)$ & $85.7 \%(78$ of 91$)$ \\
\hline Housing Conditions & $94.9 \%(657)$ & $3.5 \%(24)$ & $2.0 \%(14$ of 657$)$ & $58.3 \%(14$ of 24$)$ \\
\hline $\begin{array}{l}\text { Financial } \\
\text { Assistance }\end{array}$ & $99.0 \%(685)$ & $51.3 \%(355)$ & $36.3 \%(251$ of 685$)$ & $70.7 \%(251$ of 355$)$ \\
\hline Utilities & $96.5 \%(668)$ & $2.2 \%(15)$ & $1.7 \%(12$ of 668$)$ & $80.0 \%(12$ of 15$)$ \\
\hline Smoking & $97.5 \%(675)$ & $6.8 \%(47)$ & $6.1 \%(42$ of 675$)$ & $89.4 \%$ (42 of 47$)$ \\
\hline $\begin{array}{l}\text { Maternal } \\
\text { Depression }\end{array}$ & $94.2 \%(652)$ & $14.3 \%(99)$ & $12.0 \%(83$ of 652$)$ & $83.8 \%$ (83 of 99$)$ \\
\hline $\begin{array}{l}\text { Intimate Partner } \\
\text { Violence }\end{array}$ & $96.4 \%(667)$ & $5.1 \%(35)$ & $3.0 \%(21$ of 667$)$ & $60.0 \%(21$ of 35$)$ \\
\hline
\end{tabular}

Conclusions QI-supported DULCE expansion increased by $50 \%$ the proportion of children receiving all RHC visits and strengthened the healthcare system's capacity to proactively address families' needs via integration of existing resources.

\section{EFFECT OF DATA QUALITY IMPROVEMENT INTERVENTION ON HEALTH MANAGEMENT INFORMATION SYSTEM DATA ACCURACY: AN INTERRUPTED TIME SERIES ANALYSIS}

'Zewdie Mulissa, ${ }^{2}$ Naod Wendrad, 'Befikadu Bitewulign, ${ }^{1}$ Abera Biadgo, ${ }^{1}$ Mehiret Abate, ${ }^{1}$ Haregeweyni Alemu, ${ }^{2}$ Biruk Abate, ${ }^{1}$ Abiyou Kiflie, ${ }^{1}$ Hema Magge, ${ }^{1}$ Gareth Parry. ${ }^{1} \mathrm{IHI}$, Ethiopia; ${ }^{2} \mathrm{FMOH}$ of Ethiopia, Ethiopia

\subsection{6/bmjoq-2019-ihi.21}

Background As part of a partnership between the Institute for Healthcare Improvement and Ethiopian Federal Ministry of Health (FMoH), a Maternal and Neonatal Health (MNH) Collaborative took place between November 2016 and December 2017 aiming to accelerate reduction of maternal and neonatal mortality in Lemu Bilbilu, Tanqua Abergele and Duguna
Fango districts. Before starting the MNH Collaborative, assessments found inaccuracies in core process and outcome data obtained from Health Management Information System (HMIS) reports.

Objectives We aimed to assess the effect of an initiative to improve data quality in the $\mathrm{MNH}$ Collaborative.

Methods Building on the core $\mathrm{MNH}$ Collaborative design, data quality improvement activities were added. We used the WHO review methodology to derive a verification factor (VF) for the core measures of number of pregnant women that received antenatal care first visit, number of pregnant women that received antenatal care on at least four visits, number of pregnant women tested for syphilis and number of births attended by skilled health personnel. Impact was assessed using interrupted time series.

Results Data quality improved across all measures, for example, in Duguna Fango, the VF for number of pregnant women that received antenatal care first visit improved from 0.79 (quartiles $0.73,0.85$ ) pre-intervention to $0.99(0.93,1.00)$ post intervention, $\mathrm{p}<0.001$; and the VF for number of pregnant women tested for syphilis increased from $0.45(0.36,0.48)$ to $0.96(0.89,0.99)$, $\mathrm{p}<0.001$. 


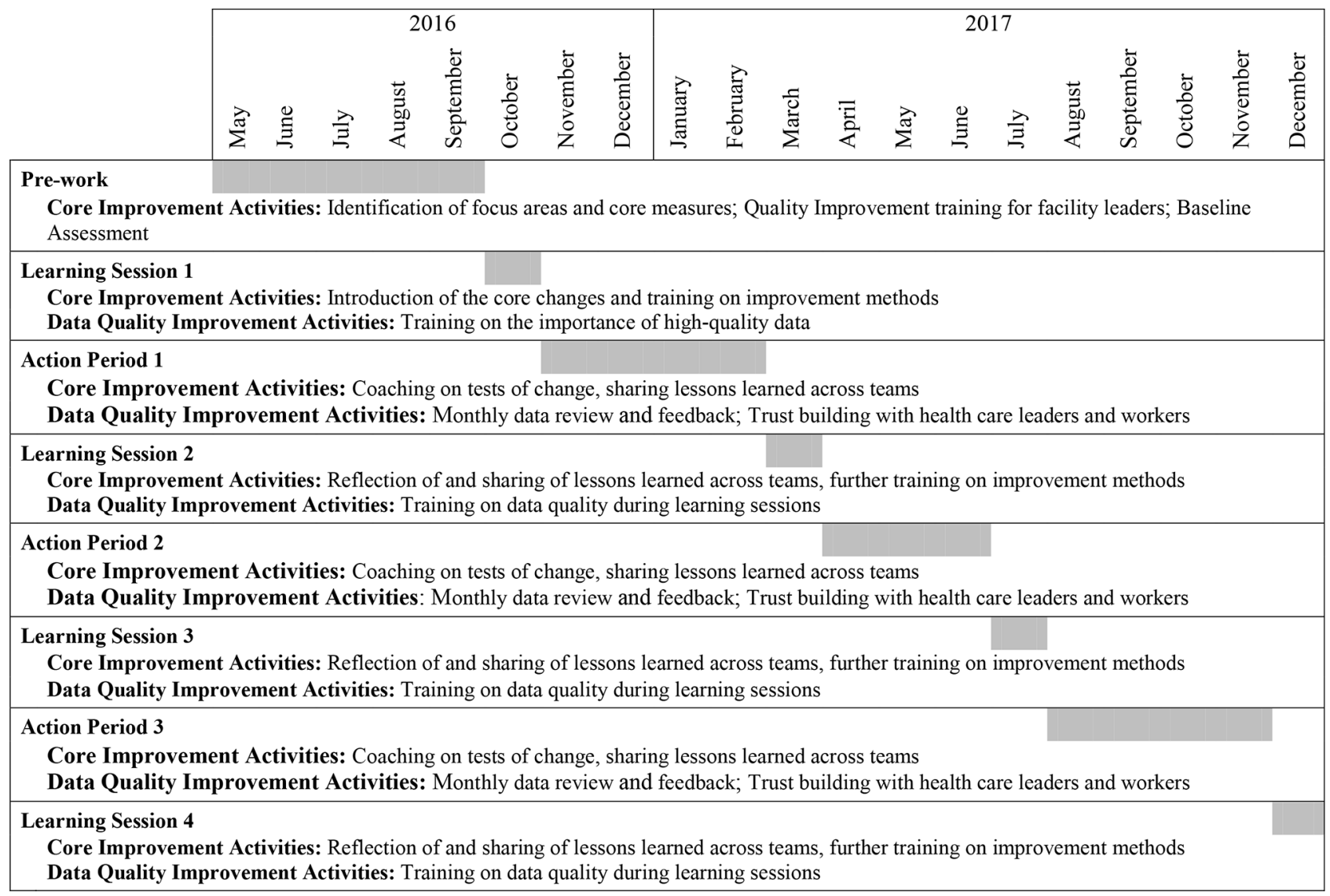

Abstract 21 Figure 1 Summary of the core improvement activities and data quality improvement activities for the maternal and neonatal health collaborative

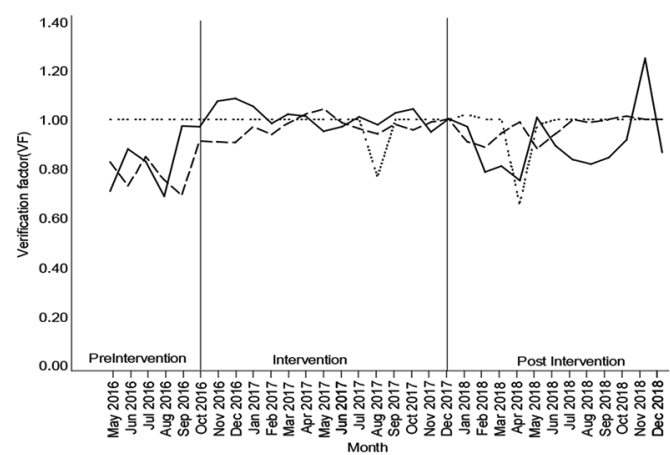

$\mathbf{a}$

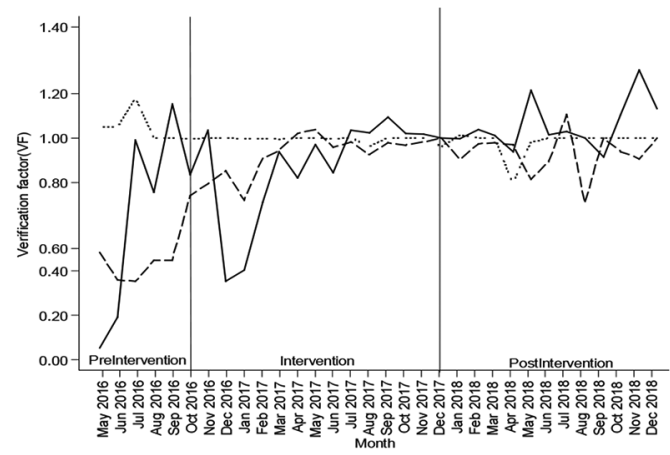

c

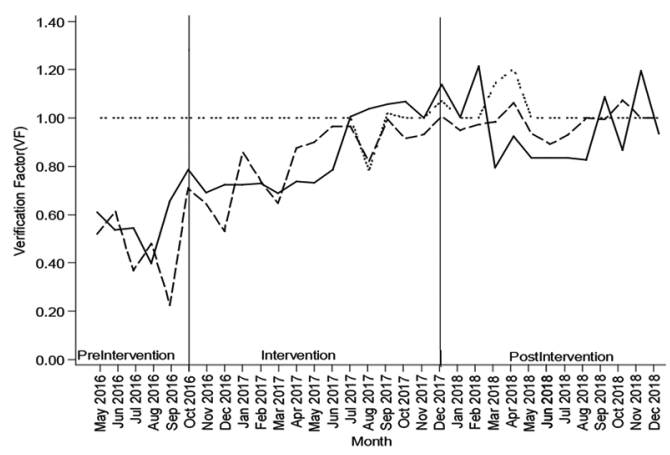

b

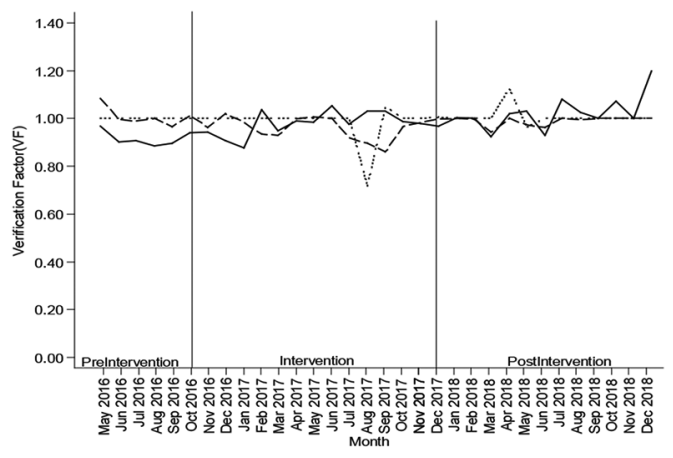

d

$$
\text { - Lemu Bilbilu _.... Tanqua Abergele _ - Duguna Fango }
$$

Abstract 21 Figure 2 (A) Antenatal care visit 1. (B) Antenatal care visit 4. (C) Syphilis screening. (D) Skilled birth attendance 
Conclusions A data quality improvement initiative significantly improved accuracy of data used to monitor maternal progress of this $\mathrm{MNH}$ Collaborative in Ethiopia.

\section{FROM NO SHOW TO ARRIVED: USING MACHINE LEARNING TO BOLSTER PATIENT ATTENDANCE FOR RESIDENT CONTINUITY-CLINIC APPOINTMENTS}

'Jaishree Hariharan, ${ }^{2}$ Roma Bhatia, 'Zachary Lenhart, 'Janice Cunningham, 'Brea Sodini, ${ }^{1}$ Dang Tran, ${ }^{1}$ Oscar Marrequin, 'Gary Fischer. ${ }^{1}$ University of Pittsburgh Medical Center, USA; ${ }^{2}$ Beth Israel Deaconess Medical Center, USA

10.1136/bmjoq-2019-ihi.22
Background Resident continuity-clinic (RCC) is a crucial component of ambulatory training in primary care.The no-show rate (NSR) in a large academic center with 60 residents averaged 27\% in academic year (AY) 2018, despite an automated phone/text reminder system 3 days prior to appointment, resulting in fragmented care, reduced access and decreased learning opportunities for residents.

Objectives To determine whether telephone outreach targeting patients predicted to be at high-risk to no-show can reduce NSR for RCC appointments.

Methods A validated machine-learning prediction model developed by data scientists at UPMC for Primary care, generated a daily list of high-risk patients (i.e. $=20 \%$ risk to no-show).

Abstract 22 Table 1 Patient characteristics: resident clinic. Unique patients scheduled in AY 2019

\begin{tabular}{|c|c|c|}
$\begin{array}{l}\text { Pt Demographics } \\
\text { AY } 2019\end{array}$ & $\begin{array}{l}\text { Unique Scheduled } \\
\text { Patients (N/\%) }\end{array}$ & $\begin{array}{l}\text { No Shows (Unique } \\
\text { Patients) (N/\%) }\end{array}$ \\
\hline Unique patients & 6230 & $1532(25 \%)$ \\
\hline Age 18-39 Yrs & $2990(48 \%)$ & $710(46 \%)$ \\
\hline Age 40-64 & $2430(39 \%)$ & $693(44 \%)$ \\
\hline Age > 65 & $810(13 \%)$ & $157(10 \%)$ \\
\hline Gender & & $841(55 \%)$ \\
\hline Female & $3606(58 \%)$ & $691(45 \%)$ \\
\hline Male & $2624(42 \%)$ & $941(61 \%)$ \\
\hline Ethnicity/Race & & $466(30 \%)$ \\
\hline Black & $2618(42 \%)$ & \\
\hline White & $2817(45 \%)$ & $376(28 \%)$ \\
\hline Insurance & & $608(45 \%)$ \\
\hline Commercial & $2625(48 \%)$ & $287(21 \%)$ \\
\hline Medicaid & $1568(29 \%)$ & \\
\hline Medicare & $1093(20 \%)$ & \\
\hline
\end{tabular}

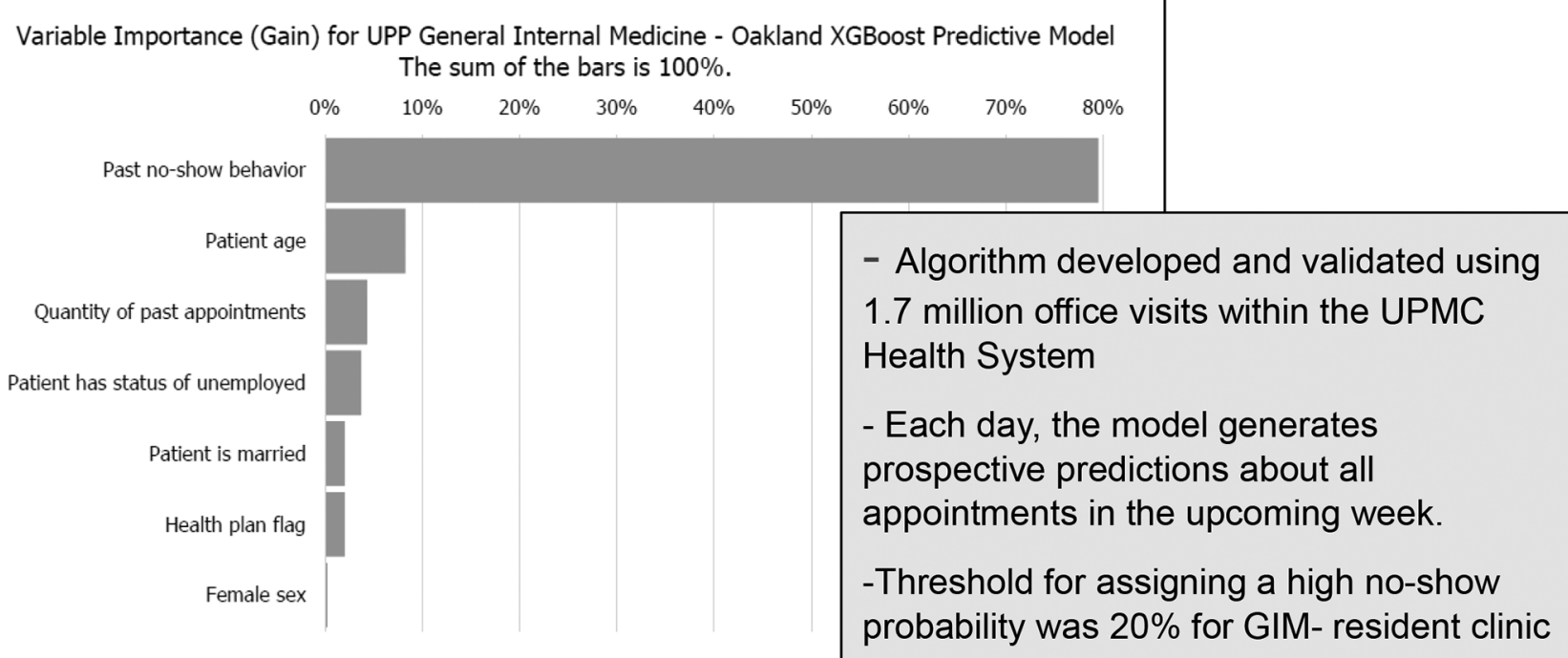

Abstract 22 Figure 1 Determinants of machine learning algorithm 